\title{
MATRIKS KOVARIANSI DALAM REGRESI NONPARAMETRIK MULTIRESPON PADA KASUS KORELASI SAMA DAN KORELASI TIDAK SAMA
}

\author{
Budi Lestari \\ Jurusan Matematika, FMIPA, Universitas Jember. \\ budilestarida@yahoo.com
}

\author{
I Nyoman Budiantara, Sony Sunaryo dan Muhammad Mashuri \\ Jurusan Statistika, FMIPA, Institut Teknologi Sepuluh Nopember, Surabaya.
}

\begin{abstract}
In the real cases, we are frequently faced the problem in which two or more dependent variables are observed at several values of the independent variables, such as at multiple time points. Multi-response nonparametric regression model, especially smoothing spline model, provides powerful tools to model the function which represents association of among the variables. The problem is how to estimate nonparametric regression curve of the multi-response nonparametric regression model. The nonparametric regression curve can be estimated using spline estimator approach, that is by carrying out penalized weighted least-squares optimation. Therefore, we need a covariance matrix which will be used as a weight of the optimation. In this paper, we determine the construction of covariance matrix for both equal and unequal of correlations cases. The results show that the covariance matrices have quite similar construction of diagonal elements but the elements outside the diagonal have very different construction that depend on the construction of the Jordan matrix.
\end{abstract}

Keywords: Correlation, Covariance Matrix, Multi-response Nonparametric Regression, Penalized Weighted Least Square.

ABSTRAK. Dalam kasus riil, seringkali ditemukan permasalahan dimana dua atau lebih variabel terikat diobservasi pada beberapa nilai variabel bebas, misalnya pada beberapa titik waktu. Model regresi nonparametrik multirespon, khususnya model penghalusan spline, memberikan alat untuk memodelkan fungsi yang menggambarkan hubungan antara variabel-variabel tersebut. Permasalahan statistik yang muncul dalam hal ini adalah masalah estimasi kurva regresi dari model regresi nonparametrik multirespon. Kurva regresi ini dapat diestimasi dengan menggunakan pendekatan estimator spline, yakni dengan cara menyelesaikan masalah optimasi penalized weighted least-squares. Oleh karena itu, diperlukan matriks kovariansi yang akan digunakan sebagai bobot dari optimasi tersebut. Dalam paper ini, dibahas cara mendapatkan konstruksi matriks kovariansi untuk kasus-kasus korelasi sama dan korelasi tidak sama. Hasil yang didapatkan menunjukkan bahwa matriks-matriks kovariansi mempunyai konstruksi elemen-elemen diagonal utama yang hampir mirip tetapi elemen-elemen di luar diagonal utama mempunyai konstruksi berbeda yang bergantung pada konstruksi matriks Jordan.

Kata kunci: Korelasi, Matriks Kovariansi, Regresi Nonparametrik Multirespon, Penalized Weighted Least Square. 


\section{PENDAHULUAN}

Fungsi yang menggambarkan hubungan antara dua atau lebih variabel terikat yang diobservasi pada beberapa nilai variabel bebas dapat dimodelkan dengan menggunakan pendekatan spline dalam regresi nonparametrik multirespon. Ada beberapa peneliti telah membahas model regresi nonparametrik untuk data multirespon. Wegman (1981); Miller dan Wegman (1987); dan Flessler (1991) memberikan algoritma untuk penghalusan spline. Wahba (1990) mengembangkan teori umum penghalusan spline dengan menggunakan reproducing kernel Hilbert space. Gooijer et al. (1991) membahas metode estimasi model regresi nonparametrik dengan error-error berkorelasi secara serial, sedangkan Fernandez dan Opsomer (2005) membahas metode estimasi model regresi nonparametrik dengan error-error berkorelasi secara spasial. Wang et al. (2000) membahas penghalusan spline untuk mengestimasi fungsi nonparametrik untuk data bivariat. Lestari et al. (2009) membahas estimator spline dalam regresi nonparametrik multirespon homoskedastik. Lestari et al. (2010) membahas estimator spline dalam regresi nonparametrik multirespon untuk kasus korelasi tidak sama.

Semua peneliti tersebut, kecuali Wang et al. (2000), Lestari et al. (2009) dan Lestari et al. (2010), mengasumsikan bahwa matriks kovariansi diketahui, dimana dalam kenyataannya kasus seperti ini jarang terjadi. Jika matriks kovariansi tidak diketahui maka harus diestimasi dari data dan hal ini dapat mempengaruhi estimasi parameter penghalus (Wang, 1998). Di samping itu, dalam regresi nonparametrik multirespon, terdapat korelasi antar respon. Oleh karena itu, masalah estimasi fungsi atau kurva regresi nonparametrik dengan menggunakan pendekatan penghalusan spline yang diperoleh dengan penyelesaian optimasi penalized weighted least-squares diperlukan suatu bobot yang ditentukan oleh matriks kovariansinya. Dalam paper ini akan dibahas bagaimana mendapatkan konstruksi matriks kovariansi pada kasus korelasi sama maupun pada kasus korelasi tidak sama. 


\section{HASIL DAN PEMBAHASAN}

\subsection{Model Regresi Nonparametrik Multirespon dengan Korelasi Sama dan}

\section{Konstruksi Matriks Kovariansinya.}

Dipandang data berpasangan $\left(t_{k j}, y_{k j}\right), \quad k=1,2, \ldots, p ; j=1,2, \ldots, n_{k}$ yang mengikuti model regresi nonparametrik multirespon ( $p$ respon) dengan korelasi sama sebagai berikut:

$$
y_{k j}=f_{k}\left(t_{k j}\right)+\varepsilon_{k j}, \quad k=1,2, \ldots, p ; j=1,2, \ldots, n_{k}
$$

dengan $f_{k}$ adalah kurva regresi yang diasumsikan mulus (smooth) dalam arti termuat di dalam ruang Sobolev $W_{2}^{m}\left[a_{k}, b_{k}\right]$, dan $\varepsilon_{k j}, j=1,2, \ldots, n_{k}$ adalah error random berdistribusi Normal secara identik dan independen dengan $E\left(\varepsilon_{k j}\right)=0$, $\operatorname{Var}\left(\varepsilon_{k j}\right)=\sigma_{k}^{2}$, sedangkan antara $\varepsilon_{k j}$ dan $\varepsilon_{l j}, \quad k \neq l$ berkorelasi dengan $\operatorname{Corr}\left(\varepsilon_{k j}, \varepsilon_{l j}\right)=\rho$.

Selanjutnya, jika dimisalkan $\underline{y}=\left(\underline{y}_{1}^{T}, \underline{y}_{2}^{T}, \ldots, \underline{y}_{p}^{T}\right), \underline{f}=\left(\underline{f}_{1}^{T}, \underline{f}_{2}^{T}, \ldots, \underline{f}_{p}^{T}\right)^{T}$, dan $\underline{\varepsilon}=\left(\underline{\varepsilon}_{1}^{T}, \underline{\varepsilon}_{2}^{T}, \ldots, \underline{\varepsilon}_{p}^{T}\right)^{T}, \quad$ dengan $\quad \underline{y}_{k}=\left(y_{k 1}, y_{k 2}, \ldots, y_{k n_{k}}\right)^{T}$, $\underline{f}_{k}=\left(f_{k}\left(t_{k 1}\right), f_{k}\left(t_{k 2}\right), \ldots, f_{k}\left(t_{k n_{k}}\right)\right)^{T}, \quad \underline{\varepsilon}_{k}=\left(\varepsilon_{k 1}, \varepsilon_{k 2}, \ldots, \varepsilon_{k n_{k}}\right)^{T}, \quad \underline{t}_{k}=\left(t_{k 1}, t_{k 2}, \ldots, t_{k n_{k}}\right)^{T}$, $k=1,2, \ldots, p$; maka dipunyai $\underline{\varepsilon}_{1}=\left(\varepsilon_{11}, \varepsilon_{12}, \ldots, \varepsilon_{1 n_{1}}\right)^{T} \sim N\left(\underline{0}, \sigma_{1}^{2} I_{1}\right), \ldots, \underline{\varepsilon}_{p}=\left(\varepsilon_{11}, \varepsilon_{12}, \ldots, \varepsilon_{1 n_{p}}\right)^{T} \sim N\left(\underline{0}, \sigma_{p}^{2} I_{p}\right)$, dengan $I_{1}$ adalah matriks identitas berukuran $\left(n_{1} \times n_{1}\right), I_{2}$ adalah matriks identitas berukuran $\left(n_{2} \times n_{2}\right)$, dan seterusnya sampai $I_{p}$ adalah matriks identitas berukuran $\left(n_{p} \times n_{p}\right)$. Oleh karena itu, persamaan (1) dapat dinyatakan dalam bentuk persamaan vektor sebagai berikut:

$$
\underline{y}=\underline{f}+\underline{\varepsilon} .
$$

Karena respon pertama, respon kedua, sampai dengan respon ke- $p$ saling berkorelasi maka estimasi fungsi atau kurva regresi nonparametrik $\underline{f}$ dengan 
menggunakan pendekatan penghalusan spline yang diperoleh dengan penyelesaian optimasi penalized weighted least-squares:

$$
\begin{aligned}
& \operatorname{Min}_{f_{1}, \ldots, f_{p} \in W_{2}}\left\{\left(\underline{y}_{1}-\underline{f}_{1}\right)^{T} W_{1}\left(\underline{y}_{1}-\underline{f}_{1}\right)+\ldots+\left(\underline{y}_{p}-\underline{f}_{p}\right)^{T} W_{p}\left(\underline{y}_{p}-\underline{f}_{p}\right)+\right. \\
& \left.\lambda_{1} \int_{a}^{b}\left(\underline{f}_{1}^{\prime \prime}(t)\right)^{2} d t+\ldots+\lambda_{p} \int_{a}^{b}\left(\underline{f}_{p}^{\prime \prime}(t)\right)^{2} d t\right\}
\end{aligned}
$$

diperlukan suatu bobot $\mathrm{W}$ yang ditentukan oleh matriks kovariansinya. Berikut ini akan ditentukan konstruksi matriks kovariansi untuk model regresi nonparametrik multirespon ( $p$ respon) dengan korelasi sama.

Berdasarkan model (2), selanjutnya ditentukan ekspektasi dari $\underline{y}$ dan kovariansi dari $\underline{y}$ yang berturut-turut diberikan sebagai berikut:

$$
\begin{aligned}
E(\underline{y})= & E\left(y_{11}, y_{12}, \ldots, y_{1 n_{1}}, y_{21}, y_{22}, \ldots, y_{2 n_{2}}, \ldots, y_{p 1}, y_{p 2}, \ldots, y_{p n_{p}}\right)^{T} \\
= & E\left(f_{1}\left(t_{11}\right)+\varepsilon_{11}, f_{1}\left(t_{12}\right)+\varepsilon_{12}, \ldots, f_{1}\left(t_{1 n_{1}}\right)+\varepsilon_{1 n_{1}}, f_{2}\left(t_{21}\right)+\varepsilon_{21}, f_{2}\left(t_{22}\right)+\varepsilon_{22}, \ldots,\right. \\
& \left.\quad f_{2}\left(t_{2 n_{2}}\right)+\varepsilon_{2 n_{2}}, \ldots, f_{p}\left(t_{p 1}\right)+\varepsilon_{p 1}, f_{p}\left(t_{p 2}\right)+\varepsilon_{p 2}, \ldots, f_{p}\left(t_{p n_{p}}\right)+\varepsilon_{p n_{p}}\right)^{T} \\
= & \underline{f}
\end{aligned}
$$

dan

$$
\begin{aligned}
\operatorname{Cov}(\underline{y})=E(\underline{y}-E(\underline{y}))(\underline{y}-E(\underline{y}))^{T}=E\left(\underline{\varepsilon}^{T}\right) \\
=\mathrm{E}\left[\varepsilon_{11}, \varepsilon_{12}, \ldots, \varepsilon_{1 n_{1}}, \varepsilon_{21}, \varepsilon_{22}, \ldots, \varepsilon_{2 n_{2}}, \ldots, \varepsilon_{p 1}, \varepsilon_{p 2}, \ldots, \varepsilon_{p n_{p}}\right]^{T}\left[\varepsilon_{11}, \varepsilon_{12}, \ldots, \varepsilon_{1 n_{1}},\right. \\
\left.\quad \varepsilon_{21}, \varepsilon_{22}, \ldots, \varepsilon_{2 n_{2}}, \ldots, \varepsilon_{p 1}, \varepsilon_{p 2}, \ldots, \varepsilon_{p n_{p}}\right]
\end{aligned}
$$




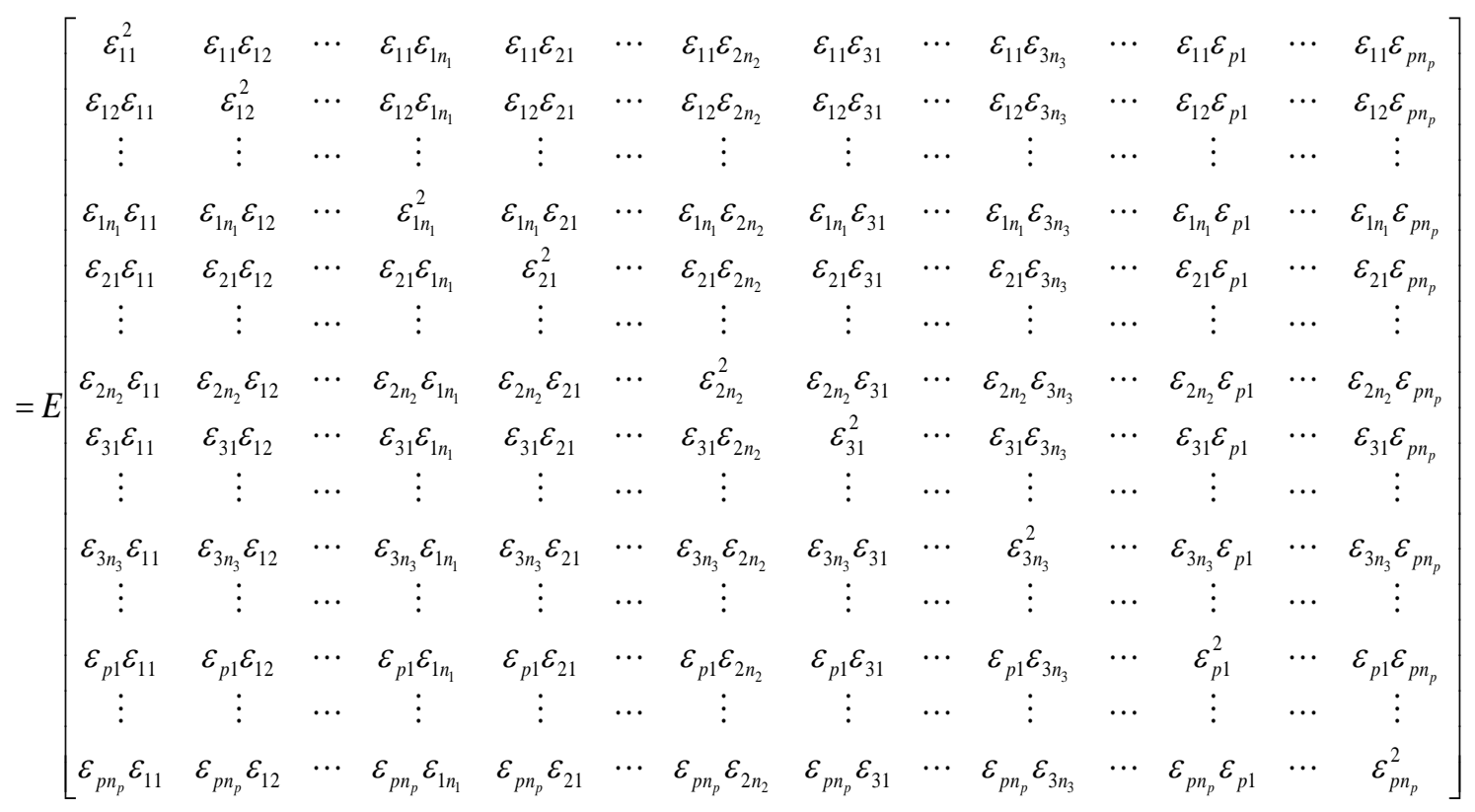$$
=\left[\begin{array}{cccccccccccccc}
\sigma_{1}^{2} & 0 & \cdots & 0 & \rho \sigma_{1} \sigma_{2} & \cdots & 0 & \rho \sigma_{1} \sigma_{3} & \cdots & 0 & \cdots & \rho \sigma_{1} \sigma_{p} & \cdots & 0 \\
0 & \sigma_{1}^{2} & \cdots & 0 & 0 & \cdots & 0 & 0 & \cdots & 0 & \cdots & 0 & \cdots & 0 \\
\vdots & \vdots & \ddots & \vdots & \vdots & \cdots & \vdots & \vdots & \cdots & \vdots & \cdots & \vdots & \cdots & \vdots \\
0 & 0 & \cdots & \sigma_{1}^{2} & 0 & \cdots & 0 & 0 & \cdots & 0 & \cdots & 0 & \cdots & 0 \\
\rho \sigma_{2} \sigma_{1} & 0 & \cdots & 0 & \sigma_{2}^{2} & \cdots & 0 & \rho \sigma_{2} \sigma_{3} & \cdots & 0 & \cdots & \rho \sigma_{2} \sigma_{p} & \cdots & 0 \\
\vdots & \vdots & \cdots & \vdots & \vdots & \ddots & \vdots & \vdots & \cdots & \vdots & \cdots & \vdots & \cdots & \vdots \\
0 & 0 & \cdots & 0 & 0 & \cdots & \sigma_{2}^{2} & 0 & \cdots & 0 & \cdots & 0 & \cdots & 0 \\
\rho \sigma_{3} \sigma_{1} & 0 & \cdots & 0 & \rho \sigma_{3} \sigma_{2} & \cdots & 0 & \sigma_{3}^{2} & \cdots & 0 & \cdots & \rho \sigma_{3} \sigma_{p} & \cdots & 0 \\
\vdots & \vdots & \cdots & \vdots & \vdots & \cdots & \vdots & \vdots & \ddots & \vdots & \cdots & \vdots & \cdots & \vdots \\
0 & 0 & \cdots & 0 & 0 & \cdots & 0 & 0 & \cdots & \sigma_{3}^{2} & \cdots & 0 & \cdots & 0 \\
\vdots & \vdots & \cdots & \vdots & \vdots & \cdots & \vdots & \vdots & \cdots & \vdots & \cdots & \vdots & \cdots & \vdots \\
\rho \sigma_{p} \sigma_{1} & 0 & \cdots & 0 & \rho \sigma_{p} \sigma_{2} & \cdots & 0 & \rho \sigma_{p} \sigma_{3} & \cdots & 0 & \cdots & \sigma_{p}^{2} & \cdots & 0 \\
\vdots & \vdots & \cdots & \vdots & \vdots & \cdots & \vdots & \vdots & \cdots & \vdots & \cdots & \vdots & \ddots & \vdots \\
0 & 0 & \cdots & 0 & 0 & \cdots & 0 & 0 & \cdots & 0 & \cdots & 0 & \cdots & \sigma_{p}^{2}
\end{array}\right]
$$$$
=\theta\left(\begin{array}{cccc}
r_{1} I_{n_{1}} & \gamma_{12} J_{12} & \cdots & \gamma_{1 p} J_{1 p} \\
\gamma_{12} J_{12}^{T} & r_{2} I_{n_{2}} & \cdots & \gamma_{2 p} J_{2 p} \\
\vdots & \vdots & \ddots & \vdots \\
\gamma_{1 p} J_{1 p}^{T} & \gamma_{2 p} J_{2 p}^{T} & \cdots & r_{p} I_{n_{p}}
\end{array}\right)=\theta W^{-1}
$$ 
dengan $\quad r_{k}=\frac{\sigma_{k}}{m}, \quad m=\prod_{\substack{j=1 \\ j \neq k}}^{p} \sigma_{j} ; \quad \theta=\prod_{k=1}^{p} \sigma_{k} ; \quad \gamma_{i j}=\frac{\rho}{\sigma_{k}}(i, j=1,2, \ldots, p ; k \neq i \neq j)$, $k=1,2, \ldots, p$; dan $J_{q s}$ adalah matriks Jordan berukuran $\left(n_{q} \times n_{s}\right)$ dengan elemen ke- $(i, j)$ sama dengan 1 jika elemen ke- $i$ dari $\underline{y}_{q}$ dan elemen ke-j dari $\underline{y}_{s}$ adalah berpasangan, dan sama dengan nol untuk yang lain (yakni jika elemen ke-i dari $\underline{y}_{q}$ dan elemen ke-j dari $\underline{y}_{s}$ tidak berpasangan); serta $I_{n_{1}}, I_{n_{2}}, \ldots, I_{n_{p}}$ adalah matriks-matriks identitas, dan

$$
W^{-1}=\left(\begin{array}{cccc}
r_{1} I_{n_{1}} & \gamma_{12} J_{12} & \cdots & \gamma_{1 p} J_{1 p} \\
\gamma_{12} J_{12}^{T} & r_{2} I_{n_{2}} & \cdots & \gamma_{2 p} J_{2 p} \\
\vdots & \vdots & \ddots & \vdots \\
\gamma_{1 p} J_{1 p}^{T} & \gamma_{2 p} J_{2 p}^{T} & \cdots & r_{p} I_{n_{p}}
\end{array}\right) .
$$

Dari (2), (4) dan (5) diperoleh bahwa respon $\underline{y}$ berdistribusi Normal multivariat dengan mean $\underline{f}$ dan variansi $\theta W^{-1}$. Matriks $W^{1}$ yang diberikan dalam (6) merupakan matriks bobot dalam persamaan (3) untuk model (1).

\subsection{Model Regresi Nonparametrik Multirespon ( $p$ respon) dengan Korelasi}

Tidak Sama dan Konstruksi Matriks Kovariansinya.

Dipandang data berpasangan $\left(t_{k j}, y_{k j}\right), \quad k=1,2, \ldots, p ; j=1,2, \ldots, n_{k} \quad$ yang mengikuti model regresi nonparametrik multirespon ( $p$ respon) dengan korelasi tidak sama sebagai berikut:

$$
y_{k j}=f_{k}\left(t_{k j}\right)+\varepsilon_{k j}, \quad k=1,2, \ldots, p ; j=1,2, \ldots, n_{k}
$$

dengan $f_{k}$ adalah kurva regresi yang diasumsikan mulus (smooth) dalam arti termuat di dalam ruang Sobolev $W_{2}^{m}\left[a_{k}, b_{k}\right]$, dan $\varepsilon_{k j}, j=1,2, \ldots, n_{k}$ adalah error random berdistribusi Normal secara identik dan independen dengan $E\left(\varepsilon_{k j}\right)=0$, $\operatorname{Var}\left(\varepsilon_{k j}\right)=\sigma_{k}^{2}$, sedangkan korelasi error antar respon diasumsikan tidak sama, yaitu $\operatorname{corr}\left(\varepsilon_{a b}, \varepsilon_{c d}\right)=\left\{\begin{array}{cc}\rho_{j} ; & a \neq c, b=d=j \\ 1 ; & a=c, b=d \\ 0 ; & b \neq d\end{array}\right.$. 
Selanjutnya, jika dimisalkan $\underline{y}=\left(\underline{y}_{1}^{T}, \underline{y}_{2}^{T}, \ldots, \underline{y}_{p}^{T}\right), \underline{f}=\left(\underline{f}_{1}^{T}, \underline{f}_{2}^{T}, \ldots, \underline{f}_{p}^{T}\right)^{T}$, dan $\underline{\varepsilon}=\left(\underline{\varepsilon}_{1}^{T}, \underline{\varepsilon}_{2}^{T}, \ldots, \underline{\varepsilon}_{p}^{T}\right)^{T}, \quad \quad$ dengan $\quad \underline{y}_{k}=\left(y_{k 1}, y_{k 2}, \ldots, y_{k n_{k}}\right)^{T}$, $\underline{f}_{k}=\left(f_{k}\left(t_{k 1}\right), f_{k}\left(t_{k 2}\right), \ldots, f_{k}\left(t_{k n_{k}}\right)\right)^{T}, \quad \underline{\varepsilon}_{k}=\left(\varepsilon_{k 1}, \varepsilon_{k 2}, \ldots, \varepsilon_{k n_{k}}\right)^{T}, \quad \underline{t}_{k}=\left(t_{k 1}, t_{k 2}, \ldots, t_{k n_{k}}\right)^{T}$, $k=1,2, \ldots, p ; \quad$ maka dipunyai $\underline{\varepsilon}_{1}=\left(\varepsilon_{11}, \varepsilon_{12}, \ldots, \varepsilon_{1 n_{1}}\right)^{T} \sim N\left(\underline{0}, \sigma_{1}^{2} I_{1}\right), \ldots, \underline{\varepsilon}_{p}=\left(\varepsilon_{11}, \varepsilon_{12}, \ldots, \varepsilon_{1 n_{p}}\right)^{T} \sim N\left(\underline{0}, \sigma_{p}^{2} I_{p}\right)$, dengan $I_{1}$ adalah matriks identitas berukuran $\left(n_{1} \times n_{1}\right), I_{2}$ adalah matriks identitas berukuran $\left(n_{2} \times n_{2}\right)$, dan seterusnya sampai $I_{p}$ adalah matriks identitas berukuran $\left(n_{p} \times n_{p}\right)$. Oleh karena itu, persamaan (7) dapat dinyatakan dalam bentuk persamaan vektor sebagai berikut:

$$
\underline{y}=\underline{f}+\underline{\varepsilon} .
$$

Oleh karena (3), berikut ini akan ditentukan konstruksi matriks kovariansi untuk model regresi nonparametrik multirespon ( $p$ respon) dengan korelasi tidak sama.

Berdasarkan model (8), selanjutnya ditentukan ekspektasi dari $\underline{y}$ dan kovariansi dari $\underline{y}$ yang berturut-turut diberikan sebagai berikut:

$$
\begin{aligned}
E(\underline{y})= & E\left(y_{11}, y_{12}, \ldots, y_{1 n_{1}}, y_{21}, y_{22}, \ldots, y_{2 n_{2}}, \ldots, y_{p 1}, y_{p 2}, \ldots, y_{p n_{p}}\right)^{T} \\
= & E\left(f_{1}\left(t_{11}\right)+\varepsilon_{11}, f_{1}\left(t_{12}\right)+\varepsilon_{12}, \ldots, f_{1}\left(t_{1 n_{1}}\right)+\varepsilon_{1 n_{1}}, f_{2}\left(t_{21}\right)+\varepsilon_{21}, f_{2}\left(t_{22}\right)+\varepsilon_{22}, \ldots,\right. \\
& \left.\quad f_{2}\left(t_{2 n_{2}}\right)+\varepsilon_{2 n_{2}}, \ldots, f_{p}\left(t_{p 1}\right)+\varepsilon_{p 1}, f_{p}\left(t_{p 2}\right)+\varepsilon_{p 2}, \ldots, f_{p}\left(t_{p n_{p}}\right)+\varepsilon_{p n_{p}}\right)^{T} \\
= & {\left[f_{1}\left(t_{11}\right), f_{1}\left(t_{12}\right), \ldots, f_{1}\left(t_{1 n_{1}}\right), f_{2}\left(t_{21}\right), f_{2}\left(t_{22}\right), \ldots, f_{2}\left(t_{2 n_{2}}\right), \ldots,\right.} \\
& \left.f_{p}\left(t_{p 1}\right), f_{p}\left(t_{p 2}\right), \ldots, f_{p}\left(t_{p n_{p}}\right)\right]^{T} \\
= & \underline{f}
\end{aligned}
$$

dan 


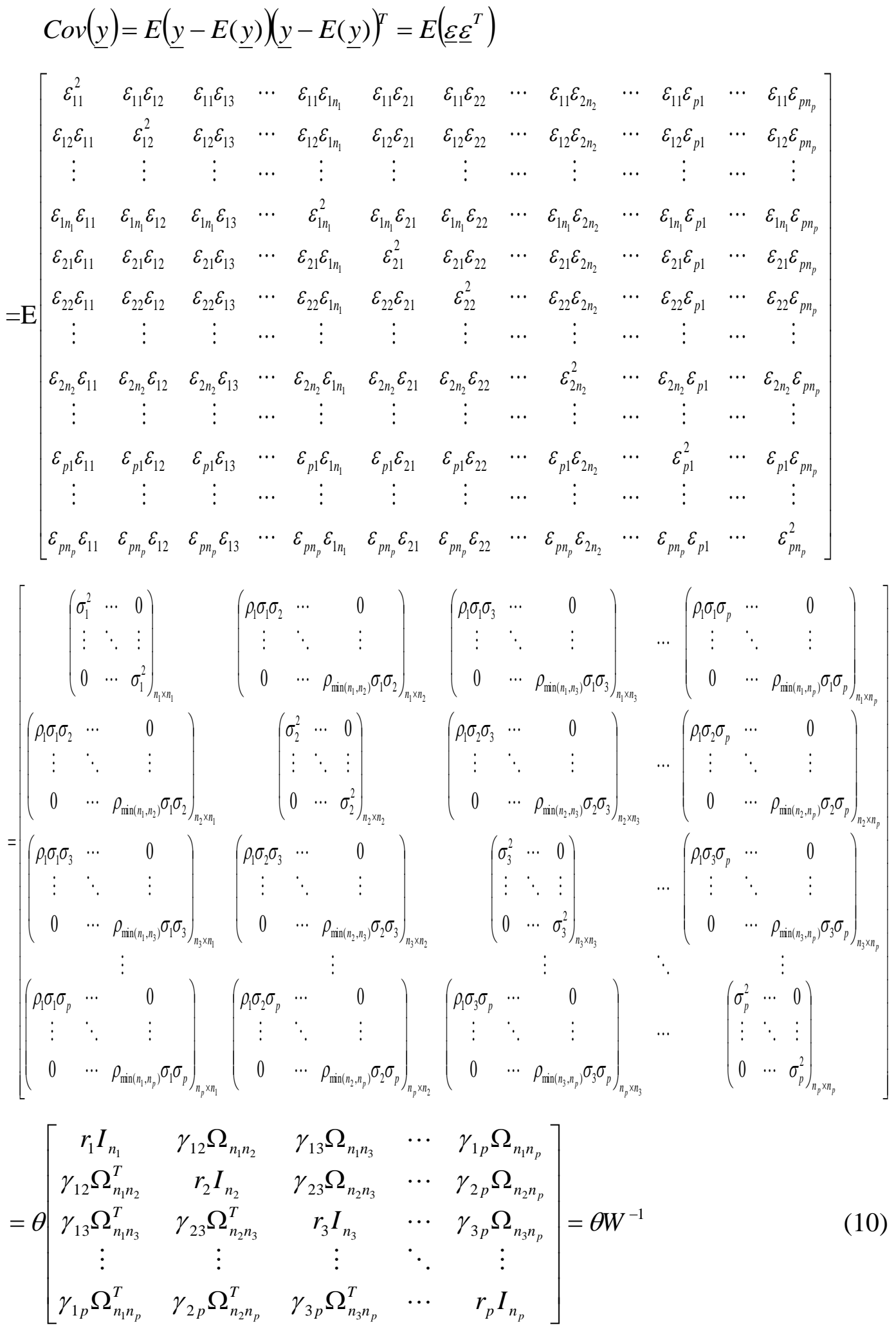

dengan: 
$W^{-1}=\left[\begin{array}{ccccc}r_{1} I_{n_{1}} & \gamma_{12} \Omega_{n_{1} n_{2}} & \gamma_{13} \Omega_{n_{1} n_{3}} & \cdots & \gamma_{1 p} \Omega_{n_{1} n_{p}} \\ \gamma_{12} \Omega_{n_{1} n_{2}}^{T} & r_{2} I_{n_{2}} & \gamma_{23} \Omega_{n_{2} n_{3}} & \cdots & \gamma_{2 p} \Omega_{n_{2} n_{p}} \\ \gamma_{13} \Omega_{n_{1} n_{3}}^{T} & \gamma_{23} \Omega_{n_{2} n_{3}}^{T} & r_{3} I_{n_{3}} & \cdots & \gamma_{3 p} \Omega_{n_{3} n_{p}} \\ \vdots & \vdots & \vdots & \ddots & \vdots \\ \gamma_{1 p} \Omega_{n_{1} n_{p}}^{T} & \gamma_{2 p} \Omega_{n_{2} n_{p}}^{T} & \gamma_{3 p} \Omega_{n_{3} n_{p}}^{T} & \cdots & r_{p} I_{n_{p}}\end{array}\right]$

$\theta=\prod_{k=1}^{p} \sigma_{k}, \quad r_{k}=\frac{\sigma_{k}}{m}, m=\prod_{\substack{j=1 \\ j \neq k}}^{p}, k=1,2, \ldots, p ; \gamma_{i j}=\frac{1}{\sigma_{k}}(i, j=1,2, \ldots, p ; k \neq i \neq j) ;$ dan $I_{n_{k}}(k=1,2, \ldots, p)$ adalah matriks identitas berukuran $n_{k} \times n_{k} ;$ serta $\Omega_{n_{i} n_{j}}$ adalah matriks Jordan berukuran $n_{i} \times n_{j}$ dengan elemen ke- $(i, j)$ sama dengan $\rho_{i}\left(i=1,2, \ldots, n_{p}\right)$ jika $i=j$, dan sama dengan nol untuk yang lain.

Dari (8), (9) dan (10) diperoleh bahwa respon $\underline{y}$ berdistribusi Normal multivariat dengan mean $\underline{f}$ dan variansi $\theta W^{-1}$. Matriks $W^{1}$ yang diberikan dalam (11) merupakan matriks bobot dalam persamaan (3) untuk model (7).

Dalam model regresi nonparametrik multirespon pada kasus korelasi tidak sama, matriks kovariansi pada (10) memenuhi empat kasus yang berkaitan dengan ukuran observasi $n$ pada setiap respon, yakni:

(1). Kasus untuk $n_{1}<n_{2}<\ldots<n_{p}$;

(2). Kasus untuk $n_{1}>n_{2}>\ldots>n_{p}$;

(3). Kasus untuk $n_{1}=n_{2}=\ldots=n_{p}$; dan

(4). Kasus selain (1), (2), dan (3), yakni kasus-kasus sebagai berikut:

(a). Tidak semua $n_{k}<n_{k+1}$, untuk $k=1,2, \ldots, p-1$;

(b). Tidak semua $n_{k}>n_{k+1}$, untuk $k=1,2, \ldots, p-1$; dan

(c). Tidak semua $n_{k}=n_{k+1}$, untuk $k=1,2, \ldots, p-1$.

Matriks-matriks kovariansi untuk keempat kasus tersebut mempunyai konstruksi sama dengan yang diberikan dalam (10). Matriks-matriks kovariansi tersebut hanya dibedakan oleh konstruksi matriks Jordan $\Omega$, yakni disesuaikan dengan masing-masing kasus ukuran observasi $n$ tersebut. 


\section{KESIMPULAN DAN SARAN}

Dari hasil yang didapatkan dapat disimpulkan bahwa matriks-matriks kovariansi mempunyai konstruksi elemen-elemen diagonal utama yang hampir mirip tetapi elemen-elemen di luar diagonal utama mempunyai konstruksi berbeda yang bergantung pada konstruksi matriks Jordan $J$ pada kasus korelasi sama, dan bergantung pada konstruksi matriks Jordan $\Omega$ pada kasus korelasi tidak sama. Untuk mendapatkan konstruksi matriks-matriks kovariansi untuk kasuskasus: tidak semua $n_{k}<n_{k+1}$, tidak semua $n_{k}>n_{k+1}$, dan tidak semua $n_{k}=n_{k+1}$, untuk $k=1,2, \ldots, p-1$ disarankan untuk memberikan contoh dengan mengambil nilai $k$ tertentu, hal ini dimaksudkan agar proses mendapatkan konstruksi matriks kovariansi menjadi lebih mudah dan singkat.

\section{DAFTAR PUSTAKA}

Flessler, J. A. (1991) Nonparametric fixed-interval smoothing with vector splines, IEEE Trans. Sig. Process., 39, 852-859.

Fernandez, F. M. dan Opsomer, J. D. (2005) Smoothing parameter selection methods for nonparametric regression with spatially correlated errors, Canadian J. Stat., 33, 279-295.

Gooijer, J. G. D., Gannoun, A. dan Larramendy, I. (1999) Nonparametric regression with serially correlated errors, Tinbergen, http://ftp.tinbergen.nl/discussionpapers/99063.pdf. diakses pada 25 Oktober 2009.

Lestari, B., Budiantara, I. N., Sunaryo, S. dan Mashuri, M. (2009) Spline estimator in homoscedastic multi-response nonparametric regression model, Proceeding of the IndoMS International Conference on Mathematics and Its Applications, Oct. 12-3, UGM, Yogyakarta, 845-854.

Lestari, B., Budiantara, I. N., Sunaryo, S. dan Mashuri, M. (2010) Spline estimator in multi-response nonparametric regression model with unequal Correlation of Errors, Journal of Mathematics and Statistics, 6(3), 327332.

Miller, J. J. dan Wegman, E. J. (1987) Vector function estimation using splines, J. Stat. Plann. Inferen., 17, 173-180. 
Wahba, G. (1990) Spline Models for Observational Data, $1^{\text {st }}$ Edition, SIAM, Philadelphia, Pennsylvania.

Wang, Y. (1998) Smoothing spline models with correlated random errors, J. Am. Stat. Assoc., 93, 341-348.

Wang, Y., Guo, W. dan Brown, M. B. (2000) Spline smoothing for bivariate data with applications to association between hormones, Statistica Sinica, 10, 377-397.

Wegman, E. J. (1981) Vector splines and estimation of filter function, Technometrics, 23, 83-89. 